This document is the accepted manuscript version of the following article:

Khomich, M., Cox, F., Andrew, C. J., Andersen, T., Kauserud, H., \& Davey, M. L. (2018). Coming up short: identifying substrate and geographic biases in fungal sequence

databases. Fungal Ecology, 36, 75-80. https://doi.org/10.1016/j.funeco.2018.08.002

This manuscript version is made available under the CC-BY-NC-ND 4.0 1icense

http://creativecommons .org/1icenses/by-nc-nd/4.0/

\title{
Coming up short: Identifying substrate and geographic biases in fungal sequence databases
}

Maryia Khomich ${ }^{1,2 *}$, Filipa Cox $^{3,4}$, Carrie J. Andrew ${ }^{5,2}$, Tom Andersen ${ }^{1}$, Håvard Kauserud ${ }^{2}$, Marie L. Davey ${ }^{2,6}$

${ }^{1}$ Section for Aquatic Biology and Toxicology, Department of Biosciences, University of Oslo,

P.O. Box 1066 Blindern, 0316 Oslo, Norway

${ }^{2}$ Section for Genetics and Evolutionary Biology, Department of Biosciences, University of Oslo,

P.O. Box 1066 Blindern, 0316 Oslo, Norway

${ }^{3}$ School of Earth and Environmental Sciences, University of Manchester, Manchester M13 9PL, United Kingdom

${ }^{4}$ British Antarctic Survey, Natural Environment Research Council, Cambridge CB3 OET, United Kingdom

${ }^{5}$ Swiss Federal Institute for Forest, Snow, and Landscape Research WSL, Zürcherstrasse 111, 8903 Birmensdorf, Switzerland

${ }^{6}$ Norwegian Institute of Bioeconomy Research, Department of Soil Quality and Climate Change, Høgskoleveien 7, 1430 Ås, Norway

*Corresponding author: Maryia Khomich, Department of Biosciences, University of Oslo, P.O. Box 1066 Blindern, 0316 Oslo, Norway

Tel.: +47-22845979, Fax: +47-22854726

E-mail address: maryia.khomich@ibv.uio.no, marykhomich@ gmail.com 


\begin{abstract}
Insufficient reference database coverage is a widely recognized limitation of molecular ecology approaches which are reliant on database matches for assignment of function or identity. Here, we use data from 65 amplicon high-throughput sequencing (HTS) datasets targeting the internal transcribed spacer (ITS) region of fungal rDNA to identify substrates and geographic areas whose underrepresentation in the available reference databases could have meaningful impact on our ability to draw ecological conclusions. A total of 14 different substrates were investigated. Database representation was particularly poor for the fungal communities found in aquatic (freshwater and marine) and soil ecosystems. Aquatic ecosystems are identified as priority targets for the recovery of novel fungal lineages. A subset of the data representing soil samples with global distribution were used to identify geographic locations and terrestrial biomes with poor database representation. Database coverage was especially poor in tropical, subtropical, and Antarctic latitudes, and the Amazon, Southeast Asia, Australasia, and the Indian subcontinent are identified as priority areas for improving database coverage in fungi.
\end{abstract}

Keywords: fungi, mycobiome, ITS region, GenBank, UNITE, RDP Bayesian classifier, diversity, metabarcoding, substrate 


\section{Introduction}

Fungi encompass one of the most functionally and ecologically diverse kingdoms of eukaryotes, maintaining ecosystem functioning on a global scale and playing fundamental roles as decomposers, mutualists and pathogens of animals and plants (Peay et al., 2016). Estimates of global fungal diversity range from 0.6 to 5.1 million species of fungi (Hawksworth, 2001, Bass \& Richards, 2011, Blackwell, 2011, Hawksworth, 2012). However, to date, only a tiny fraction of them (ca. 140000 species) have been classified, although some 1200 new fungal species are described each year (Kirk et al., 2008, Hibbett et al., 2011).

The advent of massively parallel high-throughput sequencing (HTS) has enabled the exploration of fungal diversity on a previously impossible scale (Hibbett et al., 2009). As a result, fungal barcoding of environmental samples is increasingly driving the exploration of the processes structuring fungal diversity, the identification of ecosystem functions linked to fungal diversity and the discovery of novel fungal biodiversity, especially for understudied geographic regions and substrates (Schoch et al., 2012, Öpik et al., 2016). Fungal barcoding approaches largely focus on the internal transcribed spacer (ITS) region, which is the standard barcode for Fungi (Schoch et al., 2012). The establishment of large-scale public reference ITS databases is therefore crucial to allow reliable sequence-based identification of fungal species in HTS approaches (Coissac et al., 2016).

Database-dependent HTS approaches suffer from several biases and limitations directly related to the quality and breadth of the databases. For example, there are only a relatively small fraction of reference database sequences for which a specimen or culture is readily available (Bridge et al., 2003) and consequently large proportions of environmental sequences typically are not represented in the sequence databases. In the case of Fungi, the three public repositories 
in the International Nucleotide Sequence Database Collaboration (INSDC), namely the DNA Data Bank of Japan (DDBJ), European Nucleotide Archive (ENA) and GenBank, have become a default resource of taxonomic annotation for newly generated environmental sequences (KarschMizrachi et al., 2018). However, it has been reported that 10-21\% of fungal sequences deposited in INSD can be either chimeric, of poor quality or contain incorrect and insufficient taxonomic information (Bridge et al., 2003, Nilsson et al., 2006). To improve the annotation of fungal ITS sequences from NCBI databases, the ITS RefSeq Targeted Loci project has been initiated to develop a separate, curated database representing sequences from type material and stored in public archives (Schoch et al., 2014, Robbertse et al., 2017). By contrast, UNITE (unite.ut.ee) provides highly filtered, curated ITS reference sequences for molecular identification of fungi (Kõljalg et al., 2013). The geographic representation in both databases is strongly skewed towards Europe, North America, China, and Japan (Ryberg et al., 2009, Kõljalg et al., 2013). As a result, satisfactory taxonomic assignment remains problematic in the kingdom Fungi due to the lack of reliable and correctly annotated reference sequences, and coverage related biases.

Here, we assess the impact of unbalanced database representation by geographic locale and substrate on our ability to discern and identify the components of fungal communities using data from 65 amplicon HTS datasets targeting the ITS region of rDNA. We attempt to identify both substrates and geographic regions in which underrepresentation in the available fungal ITS databases could have meaningful impact on our interpretation of HTS amplicon sequencing data.

\section{Materials and Methods}

The data analysed represent 65 next generation ITS amplicon sequencing datasets from 14 different substrates, including terrestrial, aquatic, and marine environments, as well as plant and 
animal hosts (Table S1). Data were gleaned from published materials, through personal communication with the authors, or from public data archives (e.g. ENA or NCBI Sequence Read Archive (SRA)). Among these datasets, 30 were derived from soil substrates representing 625 sites from 14 biomes with global distribution across all continents (Table S1, Table S2). Sites were assigned to biomes following the classification of the World Wildlife Foundation (http://worldwildlife.org) with the following modifications: (i) temperate deciduous forests in the Northern and Southern hemispheres were treated separately; (ii) montane forests were separated from lowland forests in the tropics; (iii) grasslands and shrublands were considered as a single unit globally, and (iv) vegetated subantarctic sites were differentiated from unvegetated maritime Antarctic sites. For all datasets, sequences were error-corrected and quality-filtered prior to clustering into operational taxonomic units (OTUs) at a 97\% similarity threshold (Table S1). Although intraspecific ITS variability ranges from zero to $24.2 \%$ (Nilsson et al., 2008), the $97 \%$ threshold is widely used to delineate fungal OTUs at approximately species level (Hughes et al., 2009, Ryberg, 2015), and the use of a single threshold across all datasets here allows for comparison across studies and geographic areas (Yahr et al., 2016). Global singletons were considered probable sequencing errors and removed (Quince et al., 2009, Kunin et al., 2010, Tedersoo et al., 2010), as were chimeric sequences. We limited analyses to only those OTUs with representative sequences $>99 \mathrm{nt}$ in length, as suggested by Tedersoo et al. (2014). BLAST searches of the representative sequences of each OTU were made against the reference databases NCBI-nr/nt (v.2.2.29) (hereafter referred to as NCBI) and UNITE v. 7 (unite.ut.ee). An alternative taxonomic assignment method, the RDP Naïve Bayesian rRNA Classifier (v. 2.11), was used to query the representative sequences against a UNITE+INSD-based database, the Warcup Fungal ITS training set 2 (Deshpande et al., 2016). The method employs multiple 
hierarchy models for several gene regions, including ITS, to bootstrap 8 nt $k$-mers of the query sequence against the reference dataset and calculate an assignment score for each taxonomic rank (Deshpande et al., 2016). OTUs were considered to be non-target and discarded if they either: (i) were identified as a non-fungal organism by any database or (ii) their best BLAST match to a fungal reference sequence had a query coverage of $<70 \%$. In total 196790 OTUs were analysed (Fig. S1, Appendix 1).

The relative representation of environmental sequences in the NCBI, UNITE, and RDP Warcup databases was assessed across substrates, biomes, and geographic locations. OTUs were considered to be represented (i.e. to have a match) in the NCBI or UNITE databases if the representative sequence had a BLAST match of $>97 \%$ identity to a sequence in the reference database. OTUs classified with $>80 \%$ confidence at a given taxonomic level using the RDP classifier were considered to be successfully taxonomically assigned. We calculated the proportion of OTUs from each substrate that were represented in the NCBI and UNITE databases, as well as the proportion of OTUs that could be successfully assigned at the phylum and genus levels using the RDP classifier. Using only the soil-inhabiting OTUs from the dataset, we also calculated the proportion of OTUs from distinct biomes that were represented in the databases and could be successfully assigned to phylum and genus. Patterns in the proportion of soil-inhabiting OTUs represented in the databases and successfully assigned at the genus level relative to latitude and longitude were investigated by fitting up to third order polynomial functions and selecting best fit models on the basis of AICc values. To account for unequal sampling intensity, observations were weighted by sampling frequency within 0.1 degree latitudinal and longitudinal ranges. To further assess geographic patterns in successful assignment of soil inhabiting OTUs, inverse distance weighting (IDW) spatial interpolation of (i) 
representation in the NCBI database, (ii) representation in the UNITE database and (iii) successful assignment at the genus level were used to estimate global database coverage. Confidence intervals for each interpolation were calculated using a jackknife estimator with 100 permutations.

\section{Results and Discussion}

On average, more OTUs were represented in NCBI than in UNITE, which is unsurprising considering the substantial size difference in the two databases. However, it must be noted that representation only denotes the existence of a similar, previously deposited sequence in the database and does not guarantee successful assignment at a given taxonomic level (Fig. 1, Fig. S2-S3, Table S1). A substantial proportion of the OTUs of most datasets could be assigned at the phylum level (mean=0.80, range=0.43-0.95), but assignment success decreased substantially at lower taxonomic levels (i.e. genus: mean=0.42, range=0.24-0.57) (Fig. S4). Across all datasets, the most OTU-rich, and therefore presumably most speciose fungal phyla were Ascomycota $(51 \%)$ and Basidiomycota (39\%). These lineages were also more successfully assigned using the RDP's ITS fungal training set 2, at both the phylum (Ascomycota: mean $=0.88$, range $=0.66-0.97$; Basidiomycota: mean=0.78, range $=0.38-0.95$ ) and genus levels (Ascomycota: mean=0.40, range $=0.19-0.56 ; \quad$ Basidiomycota: mean=0.49, range $=0.30-0.64) \quad($ Fig. S5-S6). Better representation and assignment of Dikarya compared to basal fungal lineages can likely be attributed to both primer bias in the commonly used ITS barcoding primer pairs (Bokulich \& Mills, 2013, Tedersoo \& Lindahl, 2016) and the Dikarya-biased taxonomic composition of the reference databases.

The proportions of OTUs represented in the databases and that could be successfully 
taxonomically assigned varied across all substrates, but were comparatively low in aquatic environments and soil. Only $31-46 \%$ of OTUs in these substrates were represented in the NCBI/UNITE databases, and in marine and freshwater substrates in particular, only approximately half of the fungal OTUs could be successfully assigned at the phylum level (Fig. 1, Fig. S4). The combined poor representation and lower degree of successful phylum level assignments may suggest that marine and aquatic environments host a higher proportion of novel, unclassified, and yet undescribed fungal lineages. In particular, it is thought that aquatic habitats represent a larger fraction of unknown fungal diversity than previously acknowledged (Richards et al., 2012). Despite overall low representation in the reference databases, soil had higher success rates of taxonomic assignment at the phylum level (66\%; Fig. 1) than aquatic and marine environments. This likely reflects both a highly diverse fungal community from known lineages in soil (de Boer et al., 2005), as well as database related biases due to the large number of 'unnamed environmental sequences' deposited in both NCBI and UNITE that preclude taxonomic assignment (Hibbett et al., 2011). Improved database coverage in fungi will clearly require both novel lineage characterization and attempts to link environmental sequences with identified organisms.

Although the exploration of fungal diversity across habitats worldwide has been greatly facilitated by the development of HTS approaches, the vast majority of fungal species and their distribution for most geographic regions remains unknown (Schoch et al., 2012). With the rise of molecular and HTS tools for biodiversity exploration, database breadth and quality have become integral in ensuring successful and meaningful data interpretation in these studies. In order to investigate database representation from a geographic perspective, we analysed a subset of the datasets representing soils from 625 sampling sites encompassing 14 terrestrial biomes 
worldwide (Fig. 2 and 3, Appendix 2). Database representation (i.e. the proportion of OTUs with a high quality match to a pre-existing reference sequence) varied between biomes. This suggests that: (1) fungal diversity has not been consistently explored, inventoried, and databased across all biomes and (2) there accordingly will be biome-specific biases in our ability to extract reliable database related information about fungal communities including taxonomy, guild, and trait information. Boreal, temperate coniferous, temperate deciduous and tropical montane forests are the biomes with best database representation, while dunes, mangroves, savannas and the subantarctic are among the terrestrial biomes with the poorest database representation (Fig. 2). The proportion of OTUs successfully assigned to phylum was consistent across both latitude and biomes, with the exception of the moist tropical forests. This pattern would seem to suggest that those geographic areas underrepresented in the databases harbour additional diversity among known lineages, rather than a high proportion of novel lineages forming deep branches in the tree of Kingdom Fungi (Fig. 2). The best model explaining database representation in both NCBI and UNITE, and genus-level RDP assignment was in all cases a third order polynomial fit of latitude $\left(R^{2}=0.60, R^{2}=0.34, R^{2}=0.20\right.$ respectively; Fig. 4$)$ which exhibited a clear drop in database representation towards the equator and Antarctic. No models found significant fits for longitude as an explanatory variable (data not shown). Database representation was highest in temperate, northern hemisphere latitudes while the tropics and subtropics were most poorly represented (Fig. 3, Fig. S7-S9). This trend likely reflects a combined effect of the comparatively high richness of soil fungi in the tropics in combination with lower sampling effort compared to North America and Europe (Ryberg et al., 2009). IDW identified the Amazon, Australasia, Southeast Asia and the Indian subcontinent as being particularly underrepresented in existing databases, suggesting that these geographic areas should be prioritized to improve coverage in existing 
databases.

In conclusion, with the increasing use of database dependent HTS approaches to address questions in fungal biodiversity and ecology, reference database quality is becoming an increasingly pressing concern. Public databases are dynamic and their quality has consistently improved with time and concerted effort by both users and developers (Nilsson et al., 2014, O'Leary et al., 2015). We have identified both priority substrates and geographic regions to which efforts may be focused to most efficiently advance improvement in database coverage. The combined low database representation and high proportions of OTUs that cannot be classified at high taxonomic levels observed in freshwater and marine substrates suggests they are the most likely candidates for recovery of novel lineages representing deep branches within Kingdom Fungi. Northern and temperate biomes are best represented in the databases, and tropical regions, including the Amazon and Southeast Asia, are identified as priority areas for improving global database coverage.

\section{Acknowledgements}

This study has been supported financially by the Department of Biosciences, University of Oslo and by the Research Council of Norway (grant 'COMSAT' 196336 to Tom Andersen). We thank all authors who were involved in data generation used in the meta-analysis. All data for this manuscript is properly cited and referred to in the Table S1. 


\section{References}

Bass D \& Richards TA (2011) Three reasons to re-evaluate fungal diversity 'on Earth and in the ocean'. Fungal Biology Reviews 25: 159-164.

Blackwell M (2011) The Fungi: 1, 2, 3... 5.1 million species? American Journal of Botany 98: 426-438.

Bokulich NA \& Mills DA (2013) Improved selection of internal transcribed spacer-specific primers enables quantitative, ultra-high-throughput profiling of fungal communities. Applied and environmental microbiology 79: 2519-2526.

Bridge PD, Roberts PJ, Spooner BM \& Panchal G (2003) On the unreliability of published DNA sequences. New Phytologist 160: 43-48.

Coissac E, Hollingsworth PM, Lavergne S \& Taberlet P (2016) From barcodes to genomes: extending the concept of DNA barcoding. Molecular ecology.

de Boer W, Folman LB, Summerbell RC \& Boddy L (2005) Living in a fungal world: impact of fungi on soil bacterial niche development. FEMS microbiology reviews 29: 795-811.

Deshpande V, Wang Q, Greenfield P, Charleston M, Porras-Alfaro A, Kuske CR, Cole JR, Midgley DJ \& Tran-Dinh N (2016) Fungal identification using a Bayesian classifier and the Warcup training set of internal transcribed spacer sequences. Mycologia 108: 1-5.

Hawksworth D (2012) Global species numbers of fungi: are tropical studies and molecular approaches contributing to a more robust estimate? Biodiversity and Conservation 21: 2425-2433.

Hawksworth DL (2001) The magnitude of fungal diversity: the 1. 5 million species estimate revisited. Mycological research 105: 1422-1432.

Hibbett DS, Ohman A \& Kirk PM (2009) Fungal ecology catches fire. New Phytologist 184: 279-282.

Hibbett DS, Ohman A, Glotzer D, Nuhn M, Kirk P \& Nilsson RH (2011) Progress in molecular and morphological taxon discovery in Fungi and options for formal classification of environmental sequences. Fungal Biology Reviews 25: 38-47.

Hughes KW, Petersen RH \& Lickey EB (2009) Using heterozygosity to estimate a percentage DNA sequence similarity for environmental species' delimitation across basidiomycete fungi. New Phytologist 182: 795-798.

Karsch-Mizrachi I, Takagi T \& Cochrane G (2018) The international nucleotide sequence database collaboration. Nucleic Acids Res 46: D48-D51.

Kirk P, Cannon P, Minter D \& Stalpers J (2008) Dictionary of the Fungi, 10th Edition. CABI, Wallingford, UK.

Kõljalg U, Nilsson RH, Abarenkov K, Tedersoo L, Taylor AF, Bahram M, Bates ST, Bruns TD, Bengtsson-Palme J \& Callaghan TM (2013) Towards a unified paradigm for sequence-based identification of fungi. Molecular Ecology 22: 5271-5277. 
Kunin V, Engelbrektson A, Ochman H \& Hugenholtz P (2010) Wrinkles in the rare biosphere: pyrosequencing errors can lead to artificial inflation of diversity estimates. Environmental Microbiology 12: $118-123$.

Nilsson RH, Kristiansson E, Ryberg M, Hallenberg N \& Larsson K-H (2008) Intraspecific ITS variability in the kingdom Fungi as expressed in the international sequence databases and its implications for molecular species identification. Evolutionary Bioinformatics Online 4: 193-201.

Nilsson RH, Ryberg M, Kristiansson E, Abarenkov K, Larsson K-H \& Kõljalg U (2006) Taxonomic reliability of DNA sequences in public sequence databases: a fungal perspective. PLoS One 1: e59.

Nilsson RH, Hyde KD, Pawłowska J, Ryberg M, Tedersoo L, Aas AB, Alias SA, Alves A, Anderson CL \& Antonelli A (2014) Improving ITS sequence data for identification of plant pathogenic fungi. Fungal Diversity 67: 11-19.

O'Leary NA, Wright MW, Brister JR, Ciufo S, Haddad D, McVeigh R, Rajput B, Robbertse B, SmithWhite B \& Ako-Adjei D (2015) Reference sequence (RefSeq) database at NCBI: current status, taxonomic expansion, and functional annotation. Nucleic acids research 44: D733-D745.

Peay KG, Kennedy PG \& Talbot JM (2016) Dimensions of biodiversity in the Earth mycobiome. Nature Reviews Microbiology 14: 434-447.

Quince C, Lanzén A, Curtis TP, Davenport RJ, Hall N, Head IM, Read LF \& Sloan WT (2009) Accurate determination of microbial diversity from 454 pyrosequencing data. Nature Methods 6: 639-641.

Richards TA, Jones MD, Leonard G \& Bass D (2012) Marine fungi: their ecology and molecular diversity. Annual Review of Marine Science 4: 495-522.

Robbertse B, Strope PK, Chaverri P, Gazis R, Ciufo S, Domrachev M \& Schoch CL (2017) Improving taxonomic accuracy for fungi in public sequence databases: applying 'one name one species' in welldefined genera with Trichoderma/Hypocrea as a test case. Database 2017.

Ryberg M (2015) Molecular operational taxonomic units as approximations of species in the light of evolutionary models and empirical data from Fungi. Molecular ecology 24: 5770-5777.

Ryberg M, Kristiansson E, Sjökvist E \& Nilsson RH (2009) An outlook on the fungal internal transcribed spacer sequences in GenBank and the introduction of a web-based tool for the exploration of fungal diversity. New Phytologist 181: 471-477.

Schoch CL, Seifert KA, Huhndorf S, Robert V, Spouge JL, Levesque CA, Chen W, Bolchacova E, Voigt K \& Crous PW (2012) Nuclear ribosomal internal transcribed spacer (ITS) region as a universal DNA barcode marker for Fungi. Proceedings of the National Academy of Sciences 109: 6241-6246.

Schoch CL, Robbertse B, Robert V, Vu D, Cardinali G, Irinyi L, Meyer W, Nilsson RH, Hughes K \& Miller AN (2014) Finding needles in haystacks: linking scientific names, reference specimens and molecular data for Fungi. Database 2014: bau061.

Tedersoo L \& Lindahl B (2016) Fungal identification biases in microbiome projects. Environmental Microbiology Reports 8: 774-779. 
Tedersoo L, Nilsson RH, Abarenkov K, Jairus T, Sadam A, Saar I, Bahram M, Bechem E, Chuyong G \& Kõljalg U (2010) 454 Pyrosequencing and Sanger sequencing of tropical mycorrhizal fungi provide similar results but reveal substantial methodological biases. New Phytologist 188: 291-301.

Tedersoo L, Bahram M, Põlme S, Kõljalg U, Yorou NS, Wijesundera R, Ruiz LV, Vasco-Palacios AM, Thu PQ \& Suija A (2014) Global diversity and geography of soil fungi. Science 346: 1256688.

Yahr R, Schoch CL \& Dentinger BT (2016) Scaling up discovery of hidden diversity in fungi: impacts of barcoding approaches. Phil Trans R Soc B 371: 20150336.

Öpik M, Davison J, Moora M, Pärtel M \& Zobel M (2016) Response to Comment on "Global assessment of arbuscular mycorrhizal fungus diversity reveals very low endemism”. Science 351: 826-826. 


\section{Figure legends}

Figure 1. A barplot representing proportion of assigned fungal OTUs across 14 different substrates in NCBI (green), UNITE (orange) and RDP (phylum level: blue; genus level: purple) databases.

Figure 2. A barplot representing proportion of assigned fungal OTUs across 14 different terrestrial biomes globally in NCBI (green), UNITE (orange) and RDP (phylum level: blue; genus level: purple) databases.

Figure 3. Interpolated database representation worldwide using the IDW algorithm for the (A) NCBI, (B) UNITE databases and (C) genus-level RDP assignments. Dark colours represent areas with a higher proportion of OTUs represented in the reference database. Points represent the 411 locations on which the interpolation is based.

Figure 4. Predicted fits and $95 \%$ confidence intervals for the best models (third-degree polynomial fits of latitude) explaining database representation for both the NCBI and UNITE databases, and genus-level RDP assignments. 


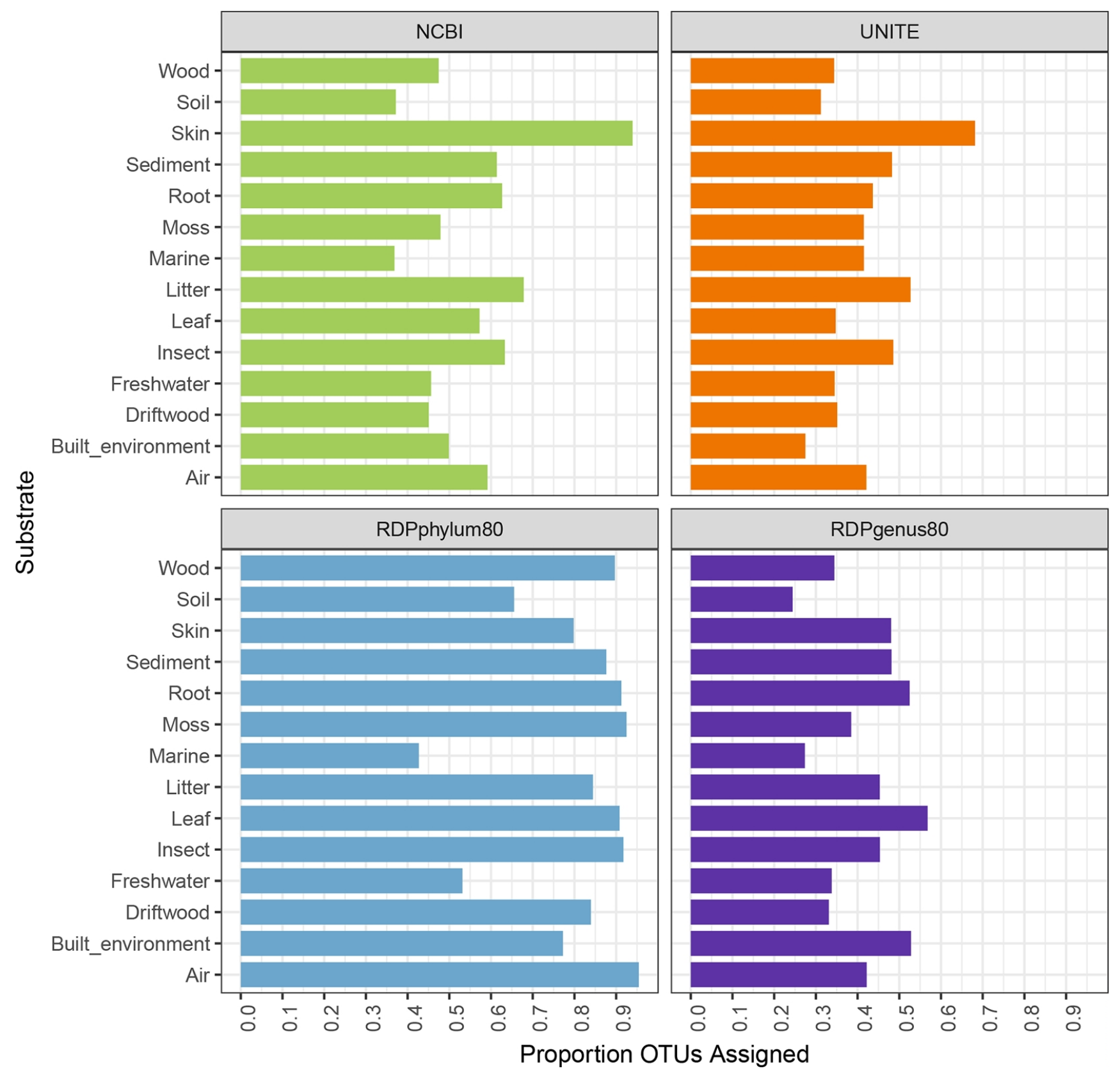




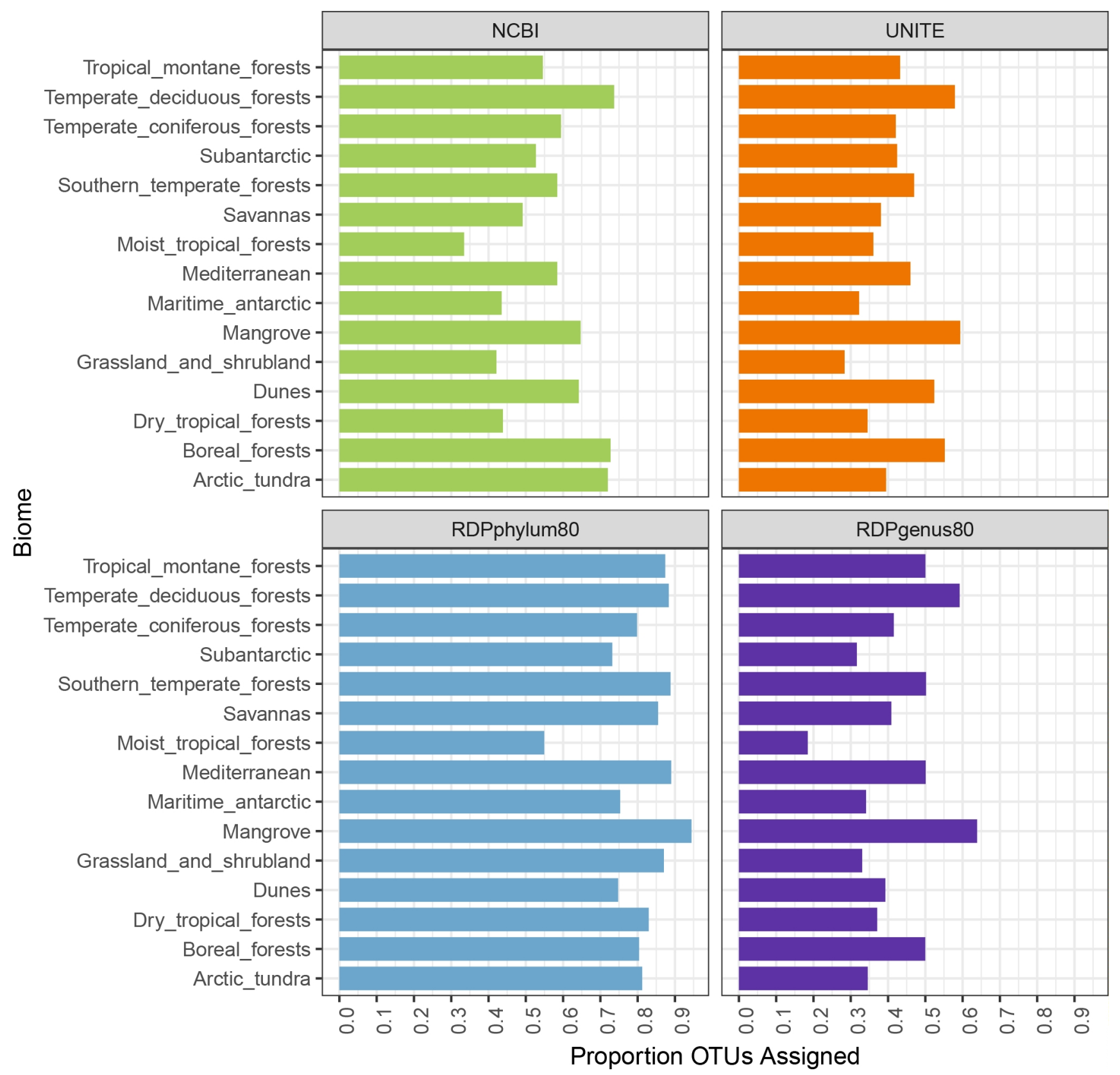



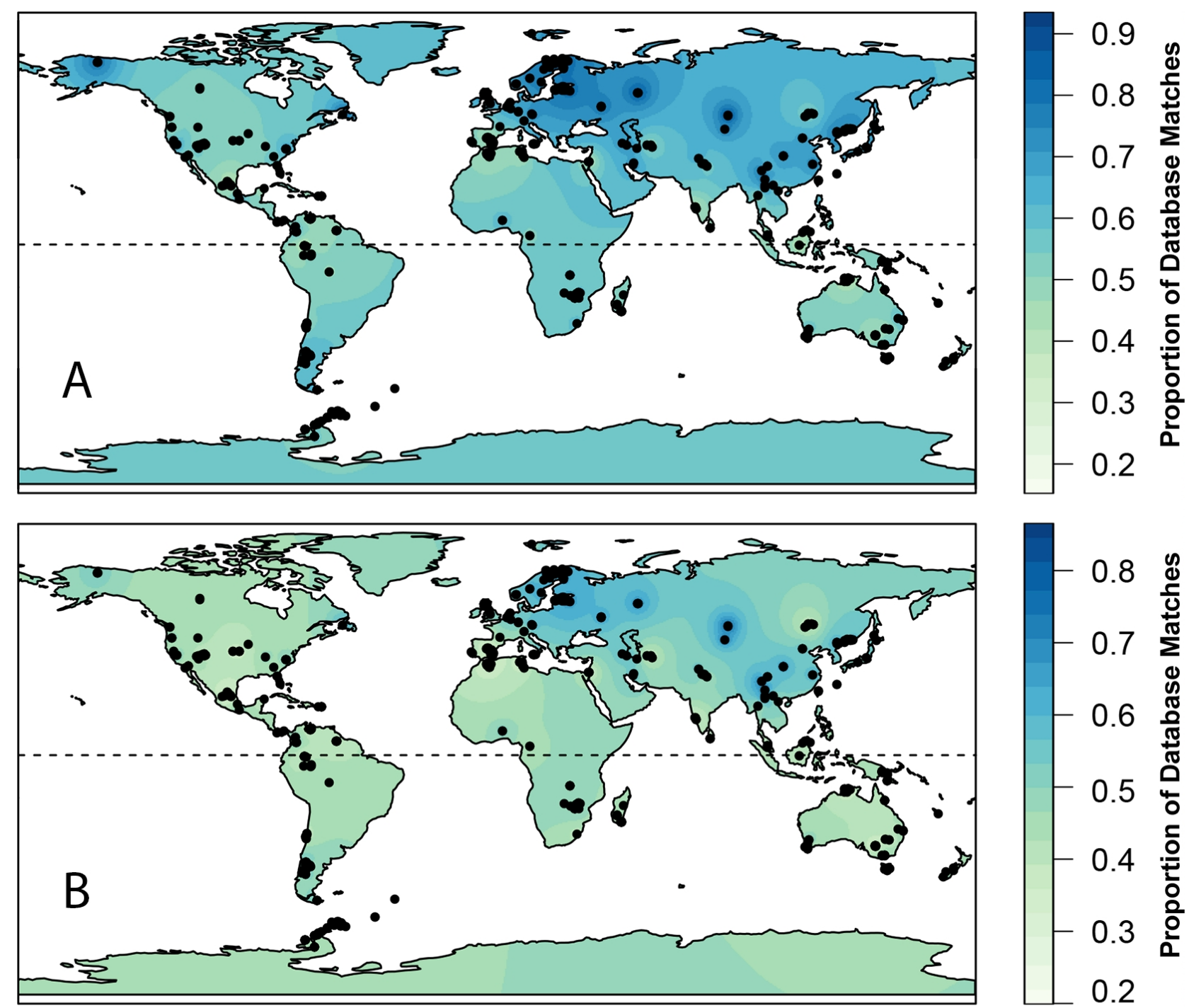

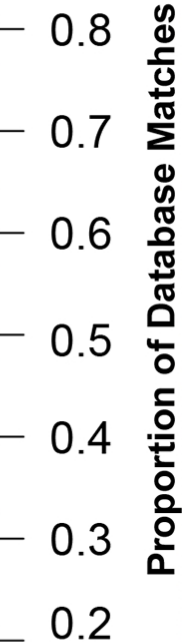

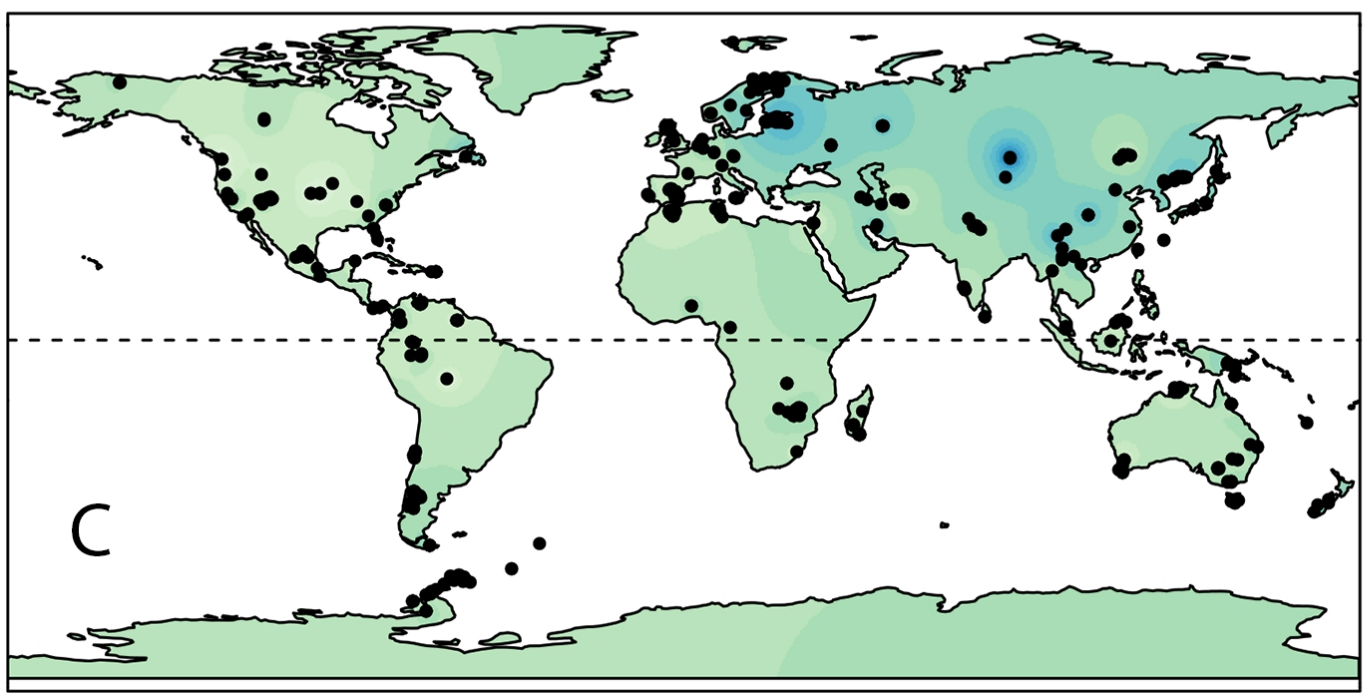

0.8

0.7

0.6 迎 $0.5 \ll$

0.4

0.3

a

0.2

0.1 


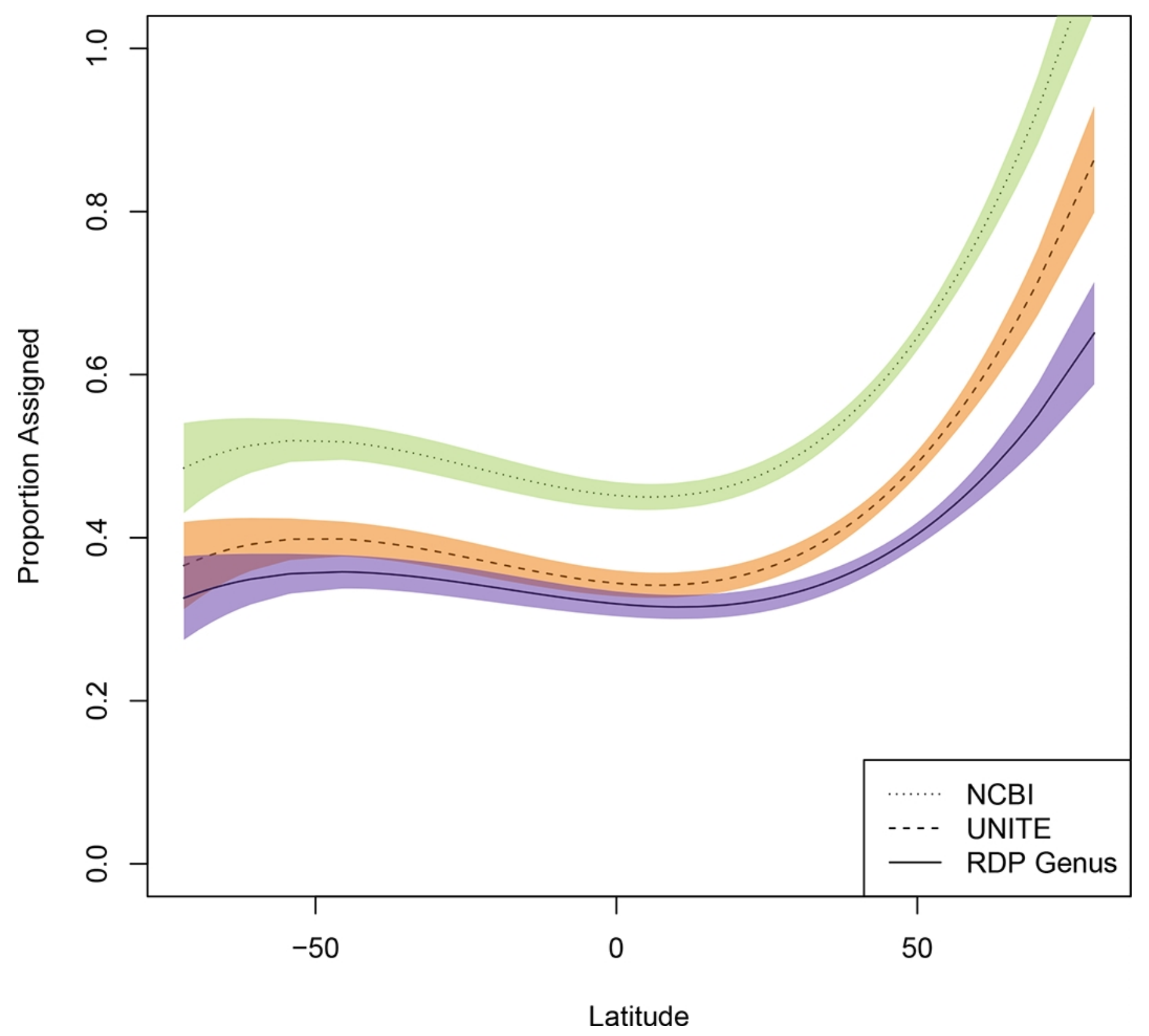




\section{Supplementary Information}

Fig. S1. A treemap of 196790 fungal OTUs across 14 different substrates. The area is proportional to the number of fungal OTUs for each substrate.

Fig. S2. A cross plot representing mean and standard deviation values of fungal OTUs for each substrate with a query coverage $>70 \%$ and sequence similarity $>70 \%$ in NCBI. Numbers in brackets indicate number of studies analysed for this substrate.

Fig. S3. A cross plot representing mean and standard deviation values of fungal OTUs for each substrate with a query coverage $>70 \%$ and sequence similarity $>70 \%$ in UNITE. Numbers in brackets indicate number of studies analysed for this substrate.

Fig. S4. A matplot representing a proportion of successfully assigned fungal OTUs across 14 different substrates identified with $>80 \%$ confidence at a given taxonomic level using the RDP classifier.

Fig. S5. A matplot representing a proportion of successfully assigned Ascomycota OTUs across 14 different substrates identified with $>80 \%$ confidence at a given taxonomic level using the RDP classifier.

Fig. S6. A matplot representing a proportion of successfully assigned Basidiomycota OTUs across 14 different substrates identified with $>80 \%$ confidence at a given taxonomic level using the RDP classifier.

Figure S7. 95\% confidence interval plot for the IDW interpolation of database representation in the NCBI database.

Figure S8. 95\% confidence interval plot for the IDW interpolation of database representation in the UNITE database.

Figure S9. 95\% confidence interval plot for the IDW interpolation of successful taxonomic 
assignment at the genus level using the RDP classifier and Warcup Fungal ITS training set 2.

Table S1. Overview of studies included in a global meta-analysis of fungal communities across 14 different substrates.

Table S2. Site, project, citation, and bioinformatic processing data for all localities in the global soil dataset.

Appendix 1. A total dataset of fungal OTUs across 14 different substrates used in the study. Appendix 2. A subset of fungal OTUs from soil representing 14 different biomes globally. 
Insect

Leaf

Moss

Soil

Root

Air 


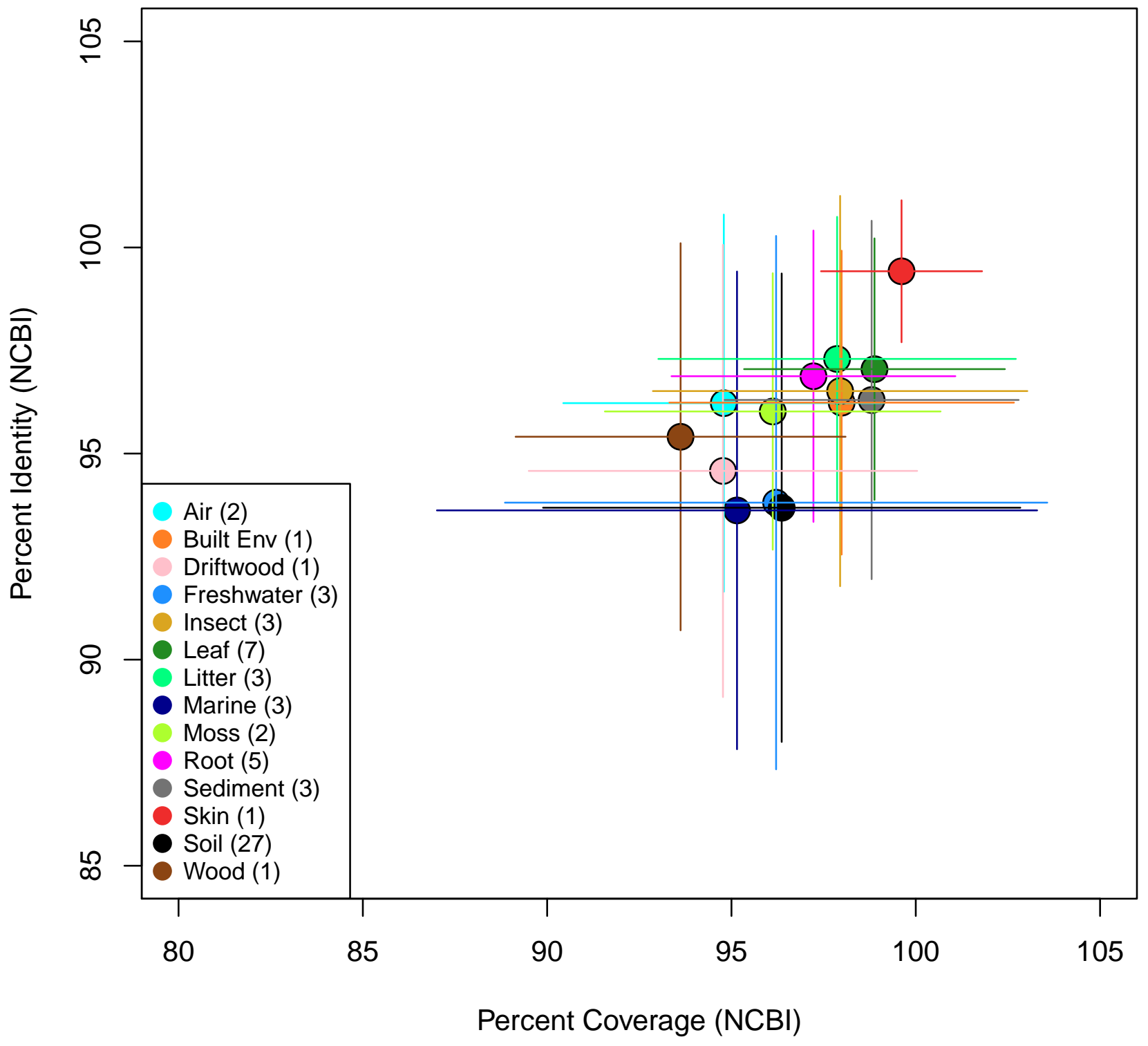




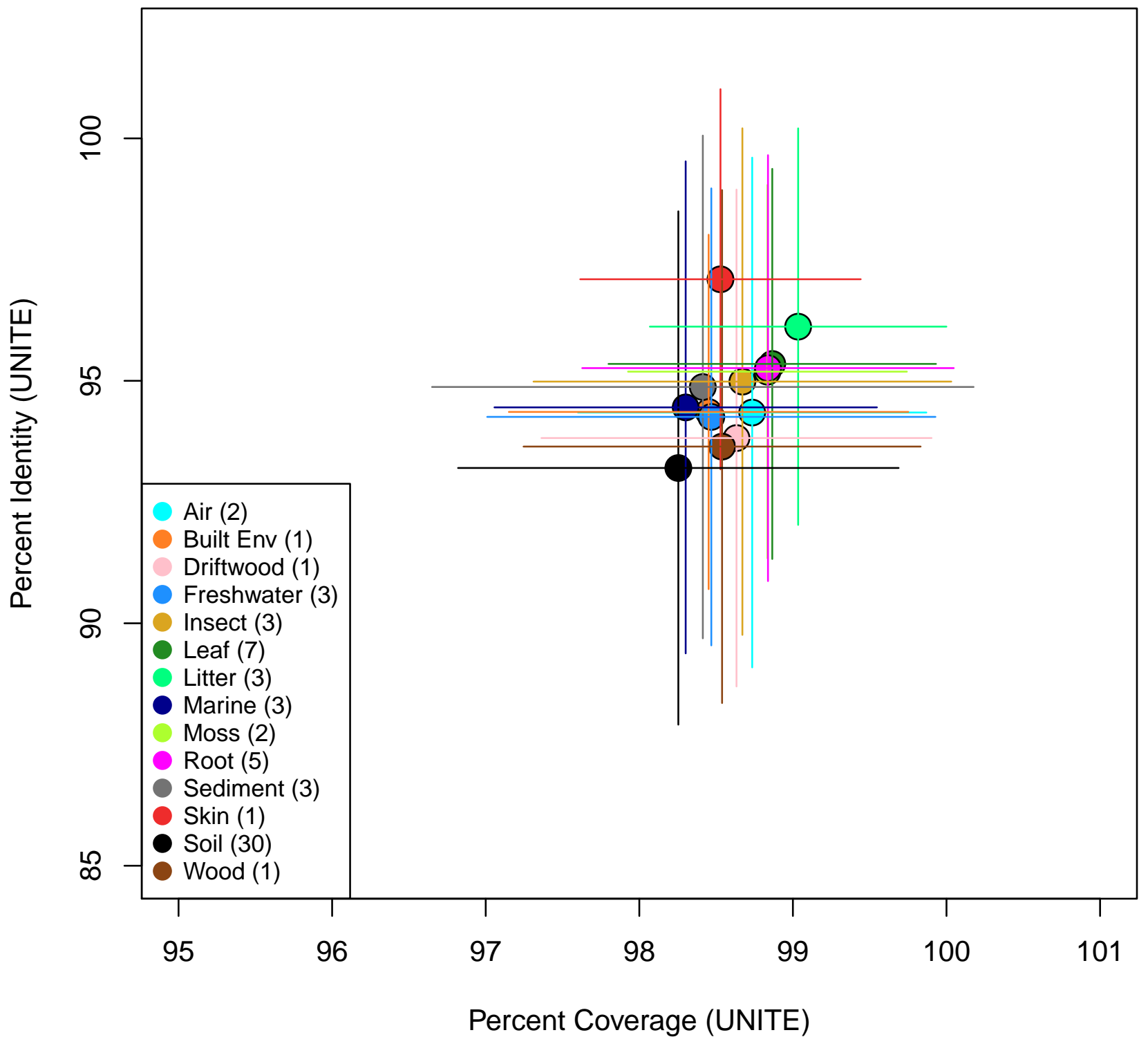




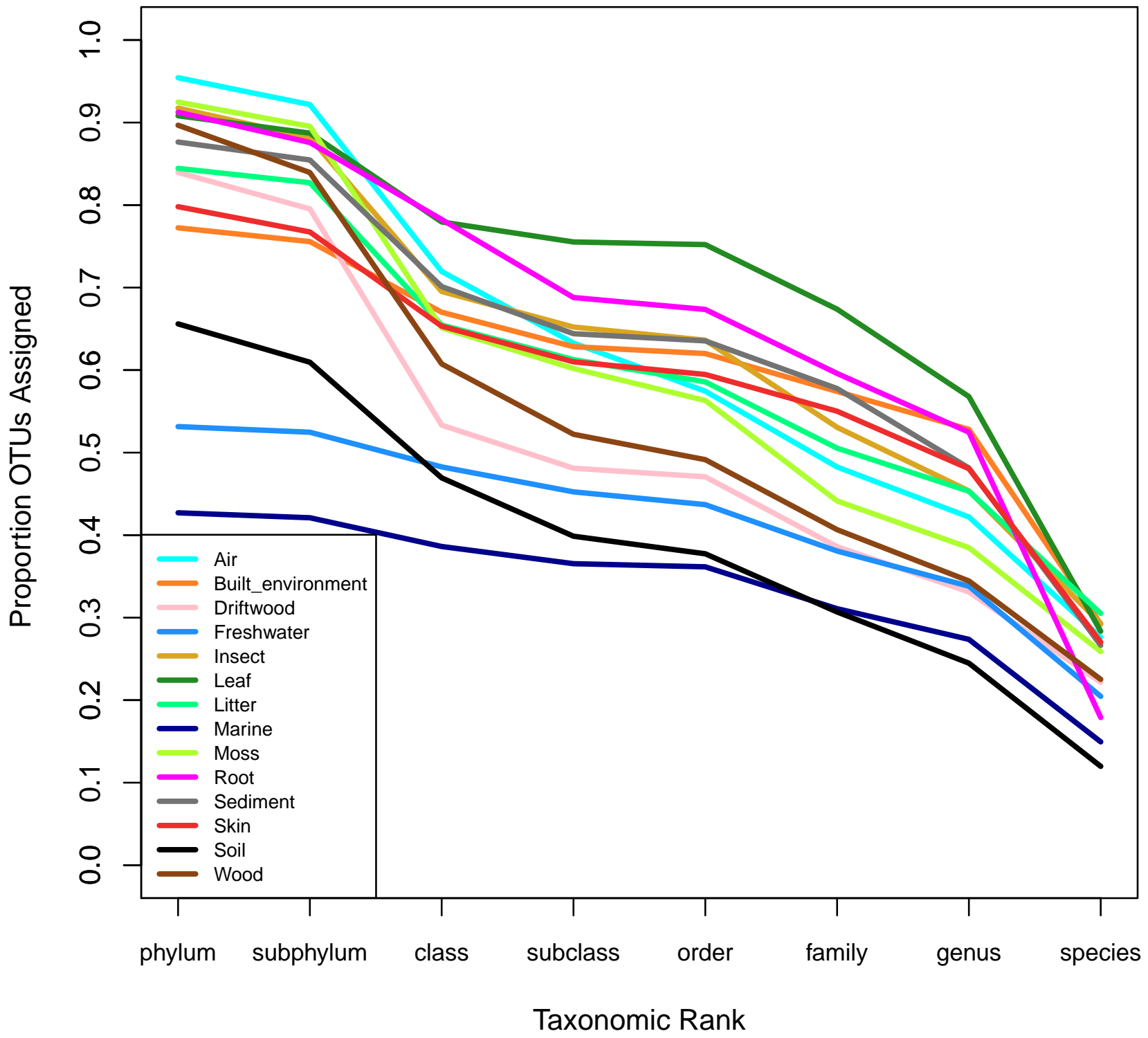




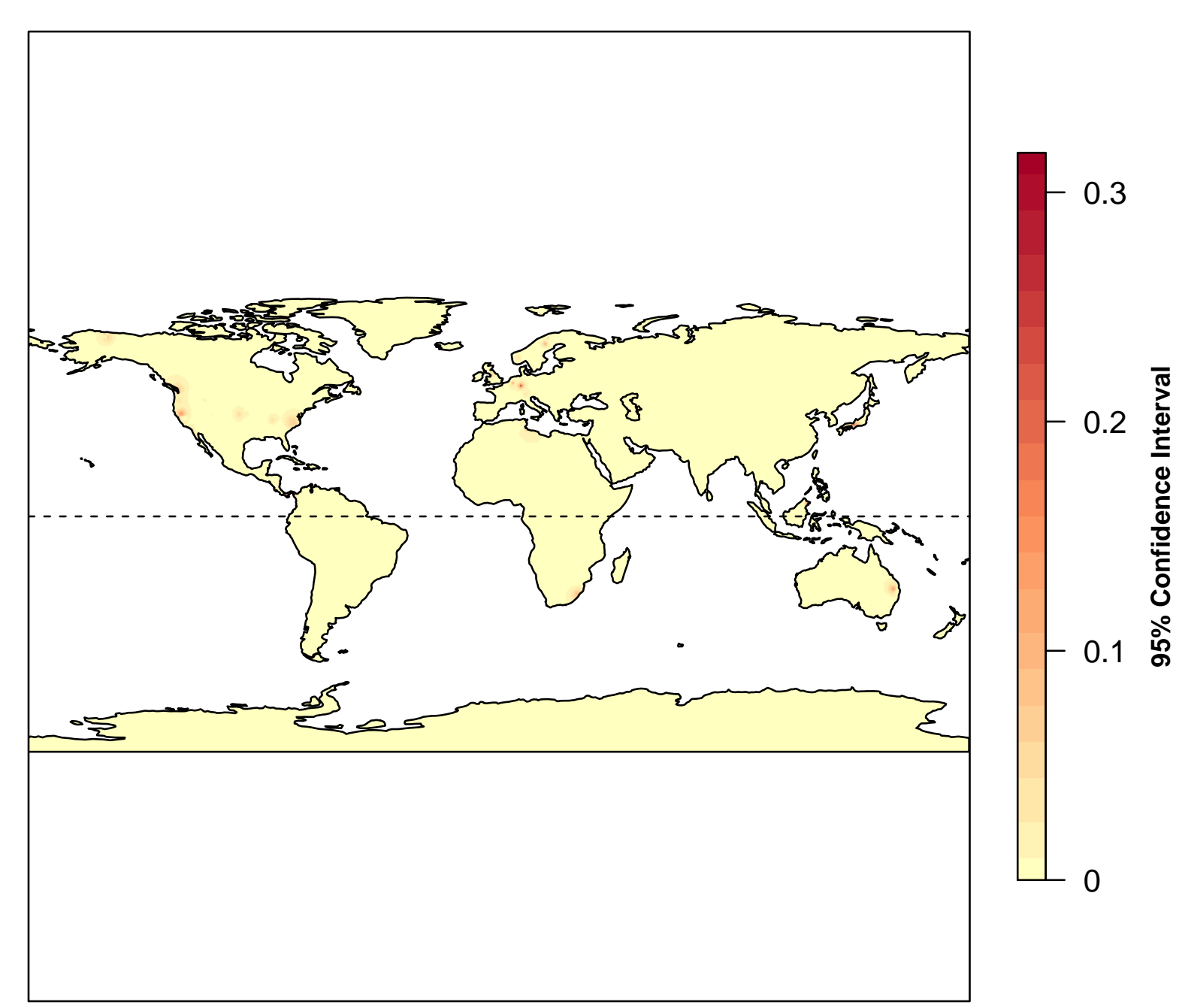




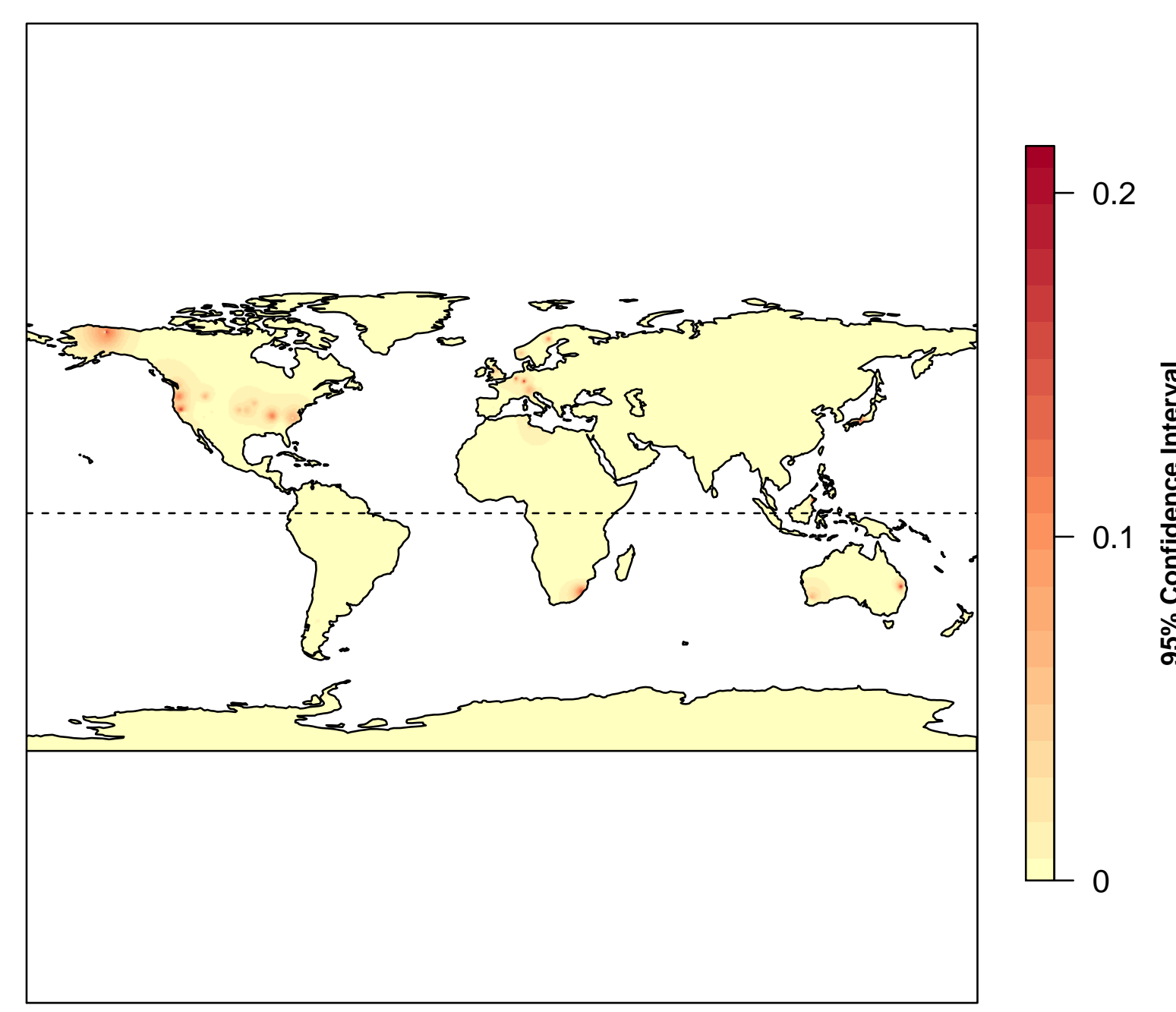




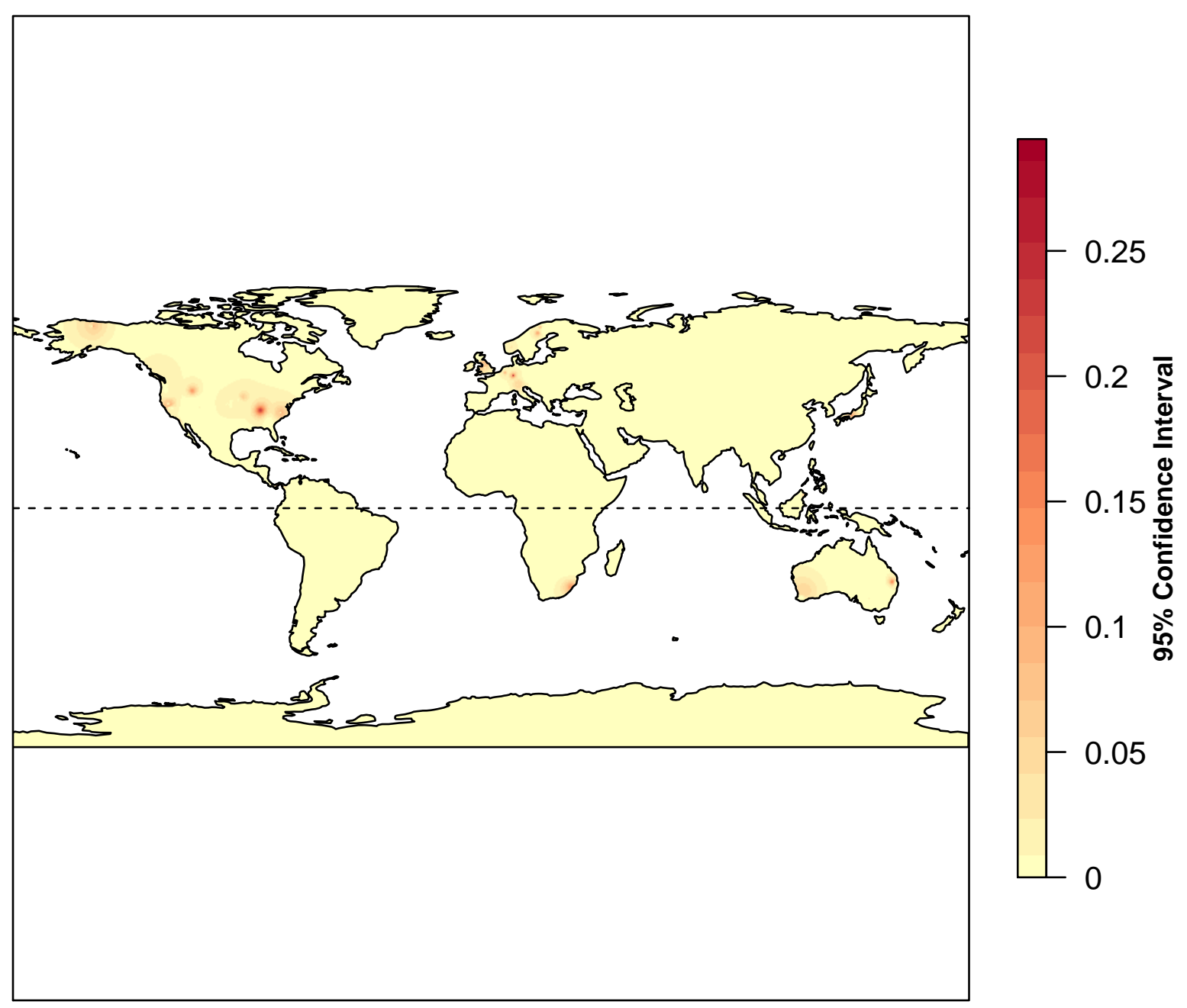


Table S1. Overview of studies included in a global meta-analysis of fungal communities across 14 different substrates.

\begin{tabular}{|c|c|c|c|c|c|c|c|c|}
\hline No. & Project & Substrate & $\begin{array}{l}\text { No. OTUs } \\
(>99 \mathrm{nt})\end{array}$ & $\begin{array}{l}\text { pident } \\
\text { NCBI }\end{array}$ & $\begin{array}{c}\text { pident } \\
\text { UNITE }\end{array}$ & $\begin{array}{c}\text { RDP } \\
\text { phylum80 }\end{array}$ & $\begin{array}{c}\text { RDP } \\
\text { genus80 }\end{array}$ & Reference \\
\hline 1 & Aas_avenella_leaf & Leaf & 198 & 0.58 & 0.45 & 0.97 & 0.51 & unpublished \\
\hline 2 & Aas_finse_root & Root & 339 & 0.69 & 0.53 & 0.86 & 0.42 & unpublished \\
\hline 3 & Aas_finse_soil & Soil & 315 & 0.65 & 0.51 & 0.75 & 0.36 & unpublished \\
\hline 4 & Adams_indoor_air & Built environment & 479 & 0.50 & 0.27 & 0.77 & 0.53 & Adams et al. (2013a) \\
\hline 5 & Adams_outdoor_air & Air & 404 & 0.45 & 0.24 & 0.86 & 0.58 & Adams et al. (2013a) \\
\hline 6 & Adams_skin & Skin & 718 & 0.94 & 0.68 & 0.80 & 0.48 & Adams et al. (2013b) \\
\hline 7 & Arfi_new_caledonia_soil & Soil & 36 & 0.65 & 0.59 & 0.94 & 0.64 & Arfi et al. (2012) \\
\hline 8 & Baerdsdatter_marine_fungi & Marine & 1602 & 0.63 & 0.90 & 0.10 & 0.07 & unpublished \\
\hline 9 & Balint_meadow_soil & Soil & 1266 & 0.50 & 0.40 & 0.88 & 0.28 & Bálint et al. (2014) \\
\hline 10 & Balint_poplar_leaf & Leaf & 182 & 0.82 & 0.64 & 0.98 & 0.75 & Bálint et al. (2013) \\
\hline 11 & Barberan_panama_soil & Soil & 20613 & 0.17 & 0.44 & 0.37 & 0.08 & Barberán et al. (2015) \\
\hline 12 & Bistorta_BioGeo & Root & 997 & 0.63 & 0.45 & 0.91 & 0.44 & Blaalid et al. (2014) \\
\hline 13 & Blaalid_finse_soil & Soil & 270 & 0.71 & 0.58 & 0.75 & 0.40 & Blaalid et al. (2013) \\
\hline 14 & Clemmensen_sweden_soil & Soil & 1617 & 0.70 & 0.51 & 0.85 & 0.38 & Clemmensen et al. (2013) \\
\hline 15 & Cordier_beech_endophyte & Leaf & 1028 & 0.96 & 0.45 & 0.85 & 0.41 & Cordier et al. (2012) \\
\hline 16 & Cox_antarctic_soil & Soil & 599 & 0.53 & 0.43 & 0.70 & 0.29 & Cox et al. (2016) \\
\hline 17 & Davey_bryophyte_gradient & Moss & 1751 & 0.54 & 0.42 & 0.95 & 0.35 & Davey et al. (2013) \\
\hline 18 & Davey_bryophyte_seasonal & Moss & 2610 & 0.44 & 0.41 & 0.91 & 0.41 & Davey et al. (2012) \\
\hline 19 & De_Beeck_belgium_soil & Soil & 177 & 0.77 & 0.68 & 0.90 & 0.49 & De Beeck et al. (2014) \\
\hline 20 & Duarte_leaf_litter & Litter & 1044 & 0.74 & 0.63 & 0.85 & 0.48 & Duarte et al. (2015) \\
\hline 21 & Geml_netherlands_soil & Soil & 3021 & 0.56 & 0.43 & 0.70 & 0.35 & Geml et al. (2014) \\
\hline 22 & Geml_arctic_alaska_soil & Soil & 5358 & 0.70 & 0.28 & 0.86 & 0.30 & Geml et al. (2016) \\
\hline
\end{tabular}




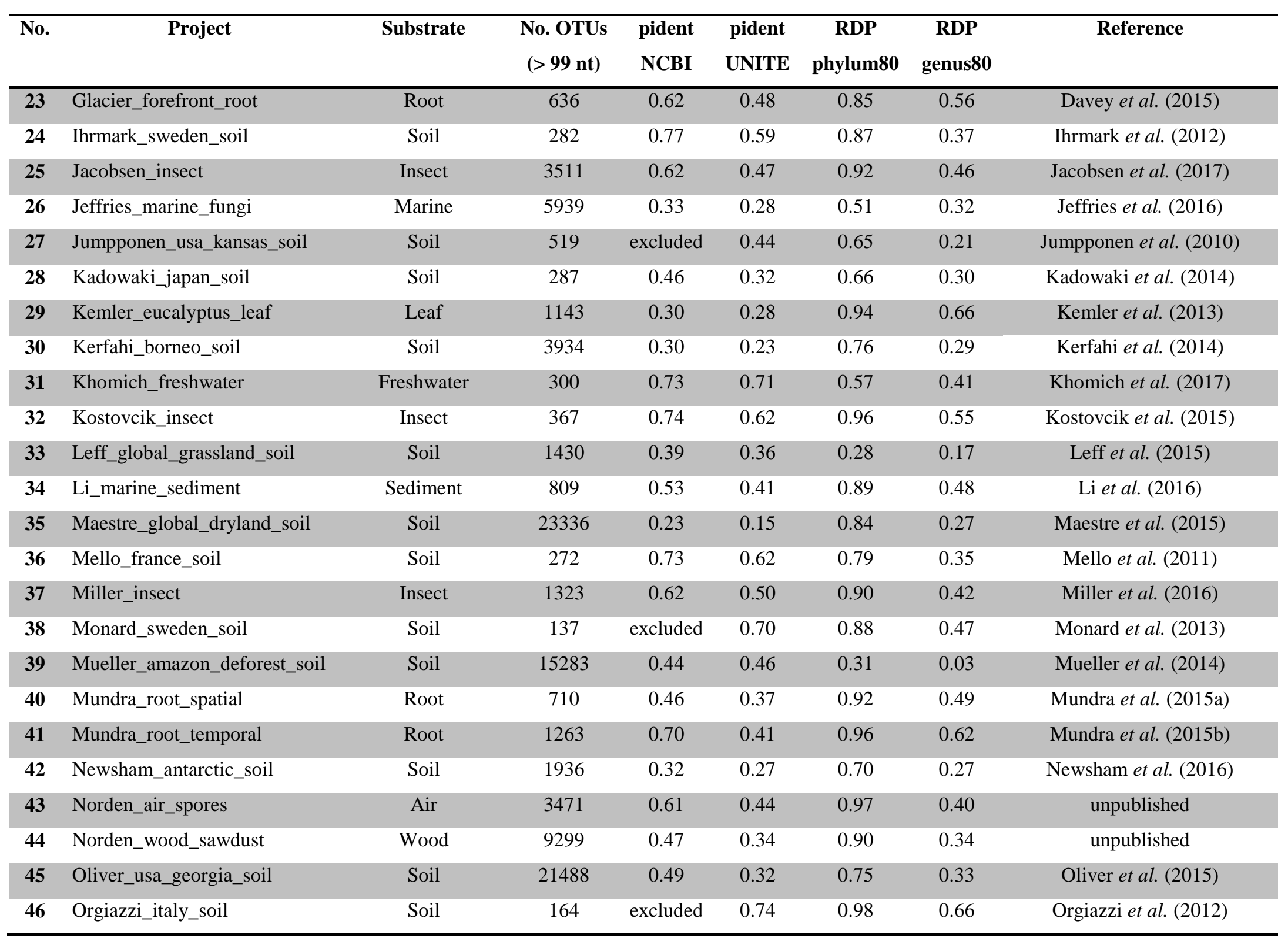




\begin{tabular}{|c|c|c|c|c|c|c|c|c|}
\hline No. & Project & Substrate & $\begin{array}{c}\text { No. OTUs } \\
(>99 \text { nt) }\end{array}$ & $\begin{array}{l}\text { pident } \\
\text { NCBI }\end{array}$ & $\begin{array}{c}\text { pident } \\
\text { UNITE }\end{array}$ & $\begin{array}{c}\text { RDP } \\
\text { phylum80 }\end{array}$ & $\begin{array}{c}\text { RDP } \\
\text { genus80 }\end{array}$ & Reference \\
\hline 47 & Porter_canada_wetland_soil & Soil & 2433 & 0.48 & 0.37 & 0.64 & 0.41 & Porter et al. (2016) \\
\hline 48 & Rama_driftwood & Driftwood & 767 & 0.45 & 0.35 & 0.84 & 0.33 & Rämä et al. (2014) \\
\hline 49 & Shi_china_lat_gradient_soil & Soil & 1000 & 0.68 & 0.59 & 0.80 & 0.54 & Shi et al. (2014) \\
\hline 50 & Siddique_beech_endophyte & Leaf & 412 & 0.67 & 0.45 & 0.79 & 0.51 & Siddique \& Unterseher (2016) \\
\hline 51 & Song_freshwater_Biwa & Freshwater & 683 & 0.38 & 0.32 & 0.53 & 0.39 & Song et al. (2017) \\
\hline 52 & Tao_Zhang_arctic_endophytes & Leaf & 250 & 0.54 & 0.36 & 0.95 & 0.39 & Zhang \& Yao (2015) \\
\hline 53 & Tao_Zhang_arctic_freshwater & Freshwater & 635 & 0.40 & 0.25 & 0.52 & 0.25 & Zhang et al. (2016a) \\
\hline 54 & Tao_Zhang_arctic_sediment & Sediment & 107 & 0.73 & 0.49 & 0.79 & 0.39 & Zhang et al. (2015) \\
\hline 55 & Taylor_coast_marine_plankton & Marine & 615 & 0.64 & 0.57 & 0.45 & 0.34 & Taylor \& Cunliffe (2016) \\
\hline 56 & Tedersoo_global_soil & Soil & 28908 & 0.36 & 0.26 & 0.81 & 0.36 & Tedersoo et al. (2014) \\
\hline 58 & Tripathi_brunei_soil & Soil & 9206 & 0.13 & 0.30 & 0.39 & 0.08 & Tripathi et al. (2016) \\
\hline 59 & Troll_Soil & Soil & 1006 & 0.57 & 0.33 & 0.52 & 0.26 & unpublished \\
\hline 60 & Unterseher_leaf & Leaf & 1450 & 0.46 & 0.26 & 0.94 & 0.64 & Unterseher et al. (2016) \\
\hline 61 & Urbina_puerto_rico_soil & Soil & 2354 & 0.28 & 0.24 & 0.79 & 0.25 & Urbina et al. (2016) \\
\hline 62 & Voriskova_oak_leaf_litter & Litter & 628 & 0.55 & 0.38 & 0.84 & 0.44 & Voříšková \& Baldrian (2013) \\
\hline 63 & X.Zhang_marine_sediment & Sediment & 694 & 0.70 & 0.56 & 0.87 & 0.50 & Zhang et al. (2016b) \\
\hline 64 & Zifcakova_forest_litter & Litter & 1029 & 0.69 & 0.52 & 0.84 & 0.43 & Žifčáková et al. (2016) \\
\hline \multirow[t]{2}{*}{65} & Zifcakova_forest_soil & Soil & 932 & 0.74 & 0.60 & 0.80 & 0.47 & Žifčáková et al. (2016) \\
\hline & & & 196790 & & & & & \\
\hline
\end{tabular}




\section{References:}

Adams RI, Miletto M, Taylor JW \& Bruns TD (2013a) Dispersal in microbes: fungi in indoor air are dominated by outdoor air and show dispersal limitation at short distances. The ISME journal 7: 12621273.

Adams RI, Miletto M, Taylor JW \& Bruns TD (2013b) The diversity and distribution of fungi on residential surfaces. PloS one 8: e78866.

Arfi Y, Marchand C, Wartel M \& Record E (2012) Fungal diversity in anoxic-sulfidic sediments in a mangrove soil. Fungal Ecology 5: 282-285.

Bálint M, Schmidt PA, Sharma R, Thines M \& Schmitt I (2014) An Illumina metabarcoding pipeline for fungi. Ecology and evolution 4: 2642-2653.

Bálint M, Tiffin P, Hallström B, O’Hara RB, Olson MS, Fankhauser JD, Piepenbring M \& Schmitt I (2013) Host genotype shapes the foliar fungal microbiome of balsam poplar (Populus balsamifera). PLoS One 8: e53987.

Barberán A, McGuire KL, Wolf JA, Jones FA, Wright SJ, Turner BL, Essene A, Hubbell SP, Faircloth BC \& Fierer N (2015) Relating belowground microbial composition to the taxonomic, phylogenetic, and functional trait distributions of trees in a tropical forest. Ecology letters 18: 1397-1405.

Blaalid R, Kumar S, Nilsson RH, Abarenkov K, Kirk P \& Kauserud H (2013) ITS1 versus ITS2 as DNA metabarcodes for fungi. Molecular Ecology Resources 13: 218-224.

Blaalid R, Davey ML, Kauserud H, Carlsen T, Halvorsen R, Høiland K \& Eidesen PB (2014) Arctic root-associated fungal community composition reflects environmental filtering. Molecular ecology 23: 649-659.

Clemmensen K, Bahr A, Ovaskainen O, Dahlberg A, Ekblad A, Wallander H, Stenlid J, Finlay R, Wardle D \& Lindahl B (2013) Roots and associated fungi drive long-term carbon sequestration in boreal forest. Science 339: 1615-1618.

Cordier T, Robin C, Capdevielle X, Desprez-Loustau M-L \& Vacher C (2012) Spatial variability of phyllosphere fungal assemblages: genetic distance predominates over geographic distance in a European beech stand (Fagus sylvatica). Fungal ecology 5: 509-520.

Cox F, Newsham KK, Bol R, Dungait JA \& Robinson CH (2016) Not poles apart: Antarctic soil fungal communities show similarities to those of the distant Arctic. Ecology letters.

Davey M, Blaalid R, Vik U, Carlsen T, Kauserud H \& Eidesen PB (2015) Primary succession of Bistorta vivipara (L.) Delabre (Polygonaceae) root-associated fungi mirrors plant succession in two glacial chronosequences. Environmental Microbiology 17: 2777-2790.

Davey ML, Heegaard E, Halvorsen R, Ohlson M \& Kauserud H (2012) Seasonal trends in the biomass and structure of bryophyte-associated fungal communities explored by 454 pyrosequencing. New Phytologist 195: 844-856.

Davey ML, Heegaard E, Halvorsen R, Kauserud H \& Ohlson M (2013) Amplicon-pyrosequencing-based detection of compositional shifts in bryophyte-associated fungal communities along an elevation gradient. 
Molecular ecology 22: 368-383.

De Beeck MO, Lievens B, Busschaert P, Declerck S, Vangronsveld J \& Colpaert JV (2014) Comparison and validation of some ITS primer pairs useful for fungal metabarcoding studies. PLoS One 9: e97629.

Duarte S, Bärlocher F, Trabulo J, Cássio F \& Pascoal C (2015) Stream-dwelling fungal decomposer communities along a gradient of eutrophication unraveled by 454 pyrosequencing. Fungal Diversity 70: $127-148$.

Geml J, Semenova TA, Morgado LN \& Welker JM (2016) Changes in composition and abundance of functional groups of arctic fungi in response to long-term summer warming. Biology Letters 12: 20160503.

Geml J, Gravendeel B, van der Gaag KJ, Neilen M, Lammers Y, Raes N, Semenova TA, de Knijff P \& Noordeloos ME (2014) The contribution of DNA metabarcoding to fungal conservation: diversity assessment, habitat partitioning and mapping red-listed fungi in protected coastal Salix repens communities in the Netherlands. PloS one 9: e99852.

Ihrmark K, Bödeker IT, Cruz-Martinez K, Friberg H, Kubartova A, Schenck J, Strid Y, Stenlid J, Brandström-Durling M \& Clemmensen KE (2012) New primers to amplify the fungal ITS2 regionevaluation by 454-sequencing of artificial and natural communities. FEMS Microbiology Ecology 82: 666-677.

Jacobsen RM, Kauserud H, Sverdrup-Thygeson A, Bjorbækmo MM \& Birkemoe T (2017) Woodinhabiting insects can function as targeted vectors for decomposer fungi. Fungal Ecology 29: 76-84.

Jeffries TC, Curlevski NJ, Brown MV, Harrison DP, Doblin MA, Petrou K, Ralph PJ \& Seymour JR (2016) Partitioning of fungal assemblages across different marine habitats. Environmental microbiology reports.

Jumpponen A, Jones KL \& Blair J (2010) Vertical distribution of fungal communities in tallgrass prairie soil. Mycologia.

Kadowaki K, Sato H, Yamamoto S, Tanabe AS, Hidaka A \& Toju H (2014) Detection of the horizontal spatial structure of soil fungal communities in a natural forest. Population ecology 56: 301-310.

Kemler M, Garnas J, Wingfield MJ, Gryzenhout M, Pillay K-A \& Slippers B (2013) Ion Torrent PGM as tool for fungal community analysis: a case study of endophytes in Eucalyptus grandis reveals high taxonomic diversity. PLoS One 8: e81718.

Kerfahi D, Tripathi BM, Lee J, Edwards DP \& Adams JM (2014) The impact of selective-logging and forest clearance for oil palm on fungal communities in Borneo. PloS one 9: e111525.

Khomich M, Davey ML, Kauserud H, Rasconi S \& Andersen T (2017) Fungal communities in Scandinavian lakes along a longitudinal gradient. Fungal Ecology 27: 36-46.

Kostovcik M, Bateman CC, Kolarik M, Stelinski LL, Jordal BH \& Hulcr J (2015) The ambrosia symbiosis is specific in some species and promiscuous in others: evidence from community pyrosequencing. The ISME journal 9: 126-138.

Leff JW, Jones SE, Prober SM, Barberán A, Borer ET, Firn JL, Harpole WS, Hobbie SE, Hofmockel KS 
\& Knops JM (2015) Consistent responses of soil microbial communities to elevated nutrient inputs in grasslands across the globe. Proceedings of the National Academy of Sciences 112: 10967-10972.

Li W, Wang MM, Wang XG, Cheng XL, Guo JJ, Bian XM \& Cai L (2016) Fungal communities in sediments of subtropical Chinese seas as estimated by DNA metabarcoding. Scientific reports 6.

Maestre FT, Delgado-Baquerizo M, Jeffries TC, Eldridge DJ, Ochoa V, Gozalo B, Quero JL, GarcíaGómez M, Gallardo A \& Ulrich W (2015) Increasing aridity reduces soil microbial diversity and abundance in global drylands. Proceedings of the National Academy of Sciences 112: 15684-15689.

Mello A, Napoli C, Murat C, Morin E, Marceddu G \& Bonfante P (2011) ITS-1 versus ITS-2 pyrosequencing: a comparison of fungal populations in truffle grounds. Mycologia 103: 1184-1193.

Miller KE, Hopkins K, Inward DJ \& Vogler AP (2016) Metabarcoding of fungal communities associated with bark beetles. Ecology and evolution.

Monard C, Gantner S \& Stenlid J (2013) Utilizing ITS1 and ITS2 to study environmental fungal diversity using pyrosequencing. FEMS microbiology ecology 84: 165-175.

Mueller RC, Paula FS, Mirza BS, Rodrigues JL, Nüsslein K \& Bohannan BJ (2014) Links between plant and fungal communities across a deforestation chronosequence in the Amazon rainforest. The ISME journal 8: 1548-1550.

Mundra S, Halvorsen R, Kauserud H, Müller E, Vik U \& Eidesen PB (2015a) Arctic fungal communities associated with roots of Bistorta vivipara do not respond to the same fine-scale edaphic gradients as the aboveground vegetation. New Phytologist 205: 1587-1597.

Mundra S, Bahram M, Tedersoo L, Kauserud H, Halvorsen R \& Eidesen PB (2015b) Temporal variation of Bistorta vivipara-associated ectomycorrhizal fungal communities in the High Arctic. Molecular ecology 24: 6289-6302.

Newsham KK, Hopkins DW, Carvalhais LC, Fretwell PT, Rushton SP, O’Donnell AG \& Dennis PG (2016) Relationship between soil fungal diversity and temperature in the maritime Antarctic. Nature Climate Change 6: 182.

Oliver AK, Callaham MA \& Jumpponen A (2015) Soil fungal communities respond compositionally to recurring frequent prescribed burning in a managed southeastern US forest ecosystem. Forest Ecology and Management 345: 1-9.

Orgiazzi A, Lumini E, Nilsson RH, Girlanda M, Vizzini A, Bonfante P \& Bianciotto V (2012) Unravelling soil fungal communities from different Mediterranean land-use backgrounds. PloS one 7: e34847.

Porter TM, Shokralla S, Baird D, Golding GB \& Hajibabaei M (2016) Ribosomal DNA and plastid markers used to sample fungal and plant communities from wetland soils reveals complementary biotas. PloS one 11: e0142759.

Rämä T, Nordén J, Davey ML, Mathiassen GH, Spatafora JW \& Kauserud H (2014) Fungi ahoy! Diversity on marine wooden substrata in the high North. Fungal Ecology 8: 46-58.

Shi L-L, Mortimer PE, Slik JF, Zou X-M, Xu J, Feng W-T \& Qiao L (2014) Variation in forest soil 
fungal diversity along a latitudinal gradient. Fungal diversity 64: 305-315.

Siddique A \& Unterseher M (2016) A cost-effective and efficient strategy for Illumina sequencing of fungal communities: A case study of beech endophytes identified elevation as main explanatory factor for diversity and community composition. Fungal Ecology 20: 175-185.

Song P, Tanabe S, Yi R, Kagami M, Liu X \& Ban S (2017) Fungal community structure at pelagic and littoral sites in Lake Biwa determined with high-throughput sequencing. Limnology 1-11.

Taylor JD \& Cunliffe M (2016) Multi-year assessment of coastal planktonic fungi reveals environmental drivers of diversity and abundance. The ISME journal.

Tedersoo L, Bahram M, Põlme S, Kõljalg U, Yorou NS, Wijesundera R, Ruiz LV, Vasco-Palacios AM, Thu PQ \& Suija A (2014) Global diversity and geography of soil fungi. Science 346: 1256688.

Toju H, Kishida O, Katayama N \& Takagi K (2016) Networks Depicting the Fine-Scale Co-Occurrences of Fungi in Soil Horizons. PloS one 11: e0165987.

Tripathi BM, Song W, Slik J, Sukri RS, Jaafar S, Dong K \& Adams JM (2016) Distinctive Tropical Forest Variants Have Unique Soil Microbial Communities, But Not Always Low Microbial Diversity. Frontiers in microbiology 7.

Unterseher M, Siddique AB, Brachmann A \& Peršoh D (2016) Diversity and Composition of the Leaf Mycobiome of Beech (Fagus sylvatica) Are Affected by Local Habitat Conditions and Leaf Biochemistry. PloS one 11: e0152878.

Urbina H, Scofield DG, Cafaro M \& Rosling A (2016) DNA-metabarcoding uncovers the diversity of soil-inhabiting fungi in the tropical island of Puerto Rico. Mycoscience 57: 217-227.

Voříšková J \& Baldrian P (2013) Fungal community on decomposing leaf litter undergoes rapid successional changes. The ISME journal 7: 477-486.

Zhang T \& Yao Y-F (2015) Endophytic fungal communities associated with vascular plants in the high arctic zone are highly diverse and host-plant specific. PloS one 10: e0130051.

Zhang T, Wang NF, Zhang YQ, Liu HY \& Yu LY (2015) Diversity and distribution of fungal communities in the marine sediments of Kongsfjorden, Svalbard (High Arctic). Scientific Reports 5: 14524.

Zhang T, Wang N-F, Zhang Y-Q, Liu H-Y \& Yu L-Y (2016a) Diversity and distribution of aquatic fungal communities in the Ny-Ålesund region, Svalbard (High Arctic). Microbial ecology 71: 543-554.

Zhang X-Y, Wang G-H, Xu X-Y, Nong X-H, Wang J, Amin M \& Qi S-H (2016b) Exploring fungal diversity in deep-sea sediments from Okinawa Trough using high-throughput Illumina sequencing. Deep Sea Research Part I: Oceanographic Research Papers 116: 99-105.

Žifč́áková L, Větrovský T, Howe A \& Baldrian P (2016) Microbial activity in forest soil reflects the changes in ecosystem properties between summer and winter. Environmental microbiology 18: 288-301. 